\title{
Correction to: IL-39 acts as a friend to pancreatic cancer
}

\author{
Alicia A. Manning ${ }^{1} \cdot$ Lei Zhao $^{2}$ - Ziwen Zhu $^{3} \cdot$ Huaping Xiao ${ }^{1}$. Chase G. Redington ${ }^{3}$. Vivi A. Ding ${ }^{1}$. \\ Theodore Stewart-Hester ${ }^{1} \cdot$ Qian Bai $^{3} \cdot$ Jacob Dunlap ${ }^{3} \cdot$ Mark R. Wakefield $^{3} \cdot$ Yujiang Fang $^{1,3,4}$
}

Published online: 22 January 2019

(c) Springer Science+Business Media, LLC, part of Springer Nature 2019

\section{Correction to: Medical Oncology (2019) 36:12 https://doi.org/10.1007/s12032-018-1236-y}

The original version of this article unfortunately contained a mistake in the text of the entire article. The word "IL-39" should read as "meteorin-like protein". This has been corrected with this correction.

\section{References}

1. Ushach I, Burkhardt AM, Martinez C, Hevezi PA, Gerber PA, Buhren BA, Schrumpf H, Valle-Rios R, Vazquez MI, Homey B, Zlotnik A. METEORIN-LIKE is a cytokine associated with barrier tissues and alternatively activated macrophages. Clin Immunol. 2015;156(2):119-27.

2. Zheng SL, Li ZY, Song J, Liu JM, Miao CY. Metrnl: a secreted protein with new emerging functions. Acta Pharmacol Sin. 2016;37(5):571-9.

3. Ushach I, Zlotnik A. Biological role of granulocyte macrophage colony-stimulating factor (GM-CSF) and macrophage colonystimulating factor (M-CSF) on cells of the myeloid lineage. J Leukoc Biol. 2016;100(3):481-9.

Alicia A. Manning and Lei Zhao have contributed equally to this work.

The original article can be found online at https://doi.org/10.1007/ s12032-018-1236-y.

Yujiang Fang

yujiang.fang@dmu.edu

1 Department of Microbiology \& Immunology, Des Moines University College of Osteopathic Medicine, Des Moines, IA 50312, USA

2 Department of Respiratory Medicine, The 2nd People's Hospital of Hefei and Hefei Hospital Affiliated to Anhui Medical University, Hefei, China

3 Department of Surgery, University of Missouri School of Medicine, Columbia, MO 65212, USA

4 Department of Microbiology, Immunology \& Pathology, Des Moines University College of Osteopathic Medicine, Des Moines, IA 50312, USA
4. Vazquez MI, Catalan-Dibene J, Zlotnik A. B cells responses and cytokine production are regulated by their immune microenvironment. Cytokine. 2015;74(2):318-26.

5. Wang X, Wei Y, Xiao H, Liu X, Zhang Y, Han G, Chen G, Hou C, Ma N, Shen B, Li Y, Egwuagu CE, Wang R. A novel IL-23p19/ Ebi3 (IL-39) cytokine mediates inflammation in Lupus-like mice. Eur J Immunol. 2016;46(6):1343-50. 